\title{
Variabilidad en fuentes secundarias de aprovisionamiento lítico: El caso del sur del lago Argentino (Santa Cruz, Argentina)
}

\author{
Nora Viviana Franco ${ }^{1}$ y Eugenio Aragón ${ }^{2}$
}

\begin{abstract}
RESUMEN
El conocimiento de las fuentes potenciales de aprovisionamiento lítico y su caracterización geoquímica son esenciales para entender las estrategias de utilización de recursos líticos empleadas por las poblaciones humanas en el pasado. En este trabajo se desarrollan los resultados exploratorios obtenidos a partir de la aplicación de una metodología regional de muestreo de la disponibilidad de recursos líticos en el área del lago Argentino, donde las fuentes secundarias potenciales de aprovisionamiento lítico son abundantes. Estos muestran la existencia de variabilidad en su disponibilidad. Los análisis geoquímicos permitieron identificar la existencia de una buena correlación entre las características geoquímicas de las rocas y su distribución espacial, además de permitir sustentar la existencia de estrategias de conservación de calcedonias y ópalos.
\end{abstract}

Palabras claves: fuentes líticas secundarias - materias primas - análisis geoquímicos.

\begin{abstract}
The knowledge of the regional structure of lithic resources and its geochemical characterization are important clues to the understanding of human strategies of raw material utilization. In this paper we describe the exploratory results obtained from the application of a regional methodology of sampling of raw material sources in the area of lake Argentino, where secondary potential raw material sources are abundant. They show the existence of variability in their availability. Geochemical analysis indicates a good correlation between the geochemical characteristics of the rocks and its spatial distribution. It was also possible to identify the existence of curational strategies of the chalcedonies and opales.
\end{abstract}

Key words: secondary lithic sources - raw material geochemical analysis.

Recibido: abril 2004. Manuscrito revisado aceptado: octubre 2004

1 CONICET - Instituto Multidisciplinario de Historia y Ciencias Humanas, Universidad de Buenos Aires. Saavedra 15, $5^{\circ}$ Piso, Capital (C. P. 1083), ARGENTINA. Email: nvfranco@ciudad.com.ar

2 CONICET - Centro de Investigaciones Geológicas, Universidad de La Plata. Calle 1, nº 644, La Plata (C. P. 1900), Provincia Buenos Aires, ARGENTINA. Email: earagon@cig.museo.unlp.edu.ar

\section{Introducción}

El conocimiento de las fuentes potenciales de aprovisionamiento lítico y su caracterización geoquímica son esenciales para entender las estrategias de utilización de recursos líticos empleadas por las poblaciones humanas en el pasado. En nuestra opinión, la mayor utilidad de estos estudios radicará en la integración de los resultados obtenidos en el marco de una teoría y de la utilización de una escala de trabajo regional.

La identificación de las fuentes de aprovisionamiento potenciales de los artefactos líticos es un problema que ha sido abordado desde hace tiempo a nivel mundial. Sin embargo, en general se trabaja con fuentes primarias de aprovisionamiento y con escasas variedades de rocas. El principal problema con que tropiezan estos estudios es el de la variabilidad existente dentro y entre las fuentes de aprovisionamiento, el que es particularmente importante en el caso de tratarse de fuentes secundarias, es decir, aquellas que han sido transportadas desde sus lugares de origen por agentes naturales como ríos o glaciares (Luedtke 1979; Nami 1992a).

En este trabajo presentamos los resultados obtenidos a partir de la aplicación de una metodología de registro de la estructura regional de recursos líticos en el sur del lago Argentino, área en que las fuentes secundarias potenciales de aprovisionamiento son abundantes.

\section{Metodología}

La escala espacial del proyecto arqueológico en el que se inserta este trabajo es amplia. Se trata de la cuenca superior del río Santa Cruz, que abarca el lago Argentino y las nacientes del río, es decir, aproximadamente $4000 \mathrm{~km}^{2}$. En el marco de esta investigación, se buscó generar información acerca de la máxima variedad de situaciones concebibles (Borrero y Carballo Marina 1998). Para poder realizar una comparación entre los dis- 
tintos sectores del espacio e integrar los datos obtenidos, era necesario tener una información de base comparable. En este sentido, cabe señalar que entendemos que no sólo es importante comprender la disponibilidad de recursos de manera espacial (es decir, en la región en general), sino también temporal, incluyendo variaciones en el corto y largo plazo (Nelson 1987).

La información geológica disponible para el área está presentada en general en una escala espacial 1:200.000 (Furque 1973). Para los problemas arqueológicos nos interesan también las fuentes potenciales de aprovisionamiento lítico de menor tamaño, que no son relevadas en los trabajos geológicos, pero que debieron ser importantes para las poblaciones en el pasado. También consideramos importante tener en cuenta las variaciones en la calidad que la materia prima presenta dentro de cada una de ellas.

La metodología de relevamiento de fuentes de aprovisionamiento empleada fue reseñada en otro trabajo (Franco y Borrero 1999). En la misma, los espacios a analizar se seleccionan sobre la base de información geológica, incluyendo sectores que a priori tienen características semejantes o parecen carecer de materias primas. Cada uno de estos espacios se recorren por una determinada cantidad de personas (1, 2 ó 3, por ejemplo) y en un tiempo acotado (p.e., 20 minutos). En este tiempo, se registra la presencia de aquellas materias primas de mejor calidad para la talla, o las que se encuentran en el registro arqueológico. Las variables relevadas son: materia prima, calidad para la talla, tamaño (se considera el diámetro máximo), forma en que se presenta (guijarros achatados, bloques, etc.) y color (en el caso en que parezcan existir variaciones entre las fuentes o en el registro arqueológico). En todos los casos, se recogen muestras para analizar en el laboratorio y se realiza un registro fotográfico.

El hecho de que se recojan las muestras de rocas permite que las determinaciones sean controladas por un geólogo, lo mismo que resolver dudas en cuanto a la calidad de la materia prima, que pueden ser evaluadas en mayor profundidad en el laboratorio. Por otra parte, estas muestras se utilizan también para realizar análisis de cortes delgados o estudios geoquímicos. Las muestras se identifican en primer lug ar, sobre la base de comparaciones macroscópicas con aquellas a las que se les realizaron cortes delgados. En el caso de rocas que no se habían reconocido previamente en la región, o en los casos en que no se posean datos previos para el área, se seleccionan macroscópicamente rocas con características semejantes y luego se analizan a nivel microscópico algunas de ellas.

La identificación de la calidad de la materia prima para la talla por percusión se realiza de manera macroscópica y en relación con la experiencia previa. Consideramos importante esta distinción, ya que la calidad varía aún dentro de la misma materia prima. En otras regiones, esta diferenciación ha servido para sustentar modelos de asentamiento de distintos grupos y/o postular la existencia de economía en el uso de materias primas (p.e., Bamforth 1986; Geneste 1988; Lurie 1989; Beck y Jones 1990; Dunbar 1991; Franco 1991, 1994; Lepper y Meltzer 1991; Amick 1994; Franco y García 1994 Ms).

La escala que utilizamos para identificar la calidad de las rocas es nominal. Las mismas se clasifican en excelentes, muy buenas, buenas y regulares, de acuerdo con su homogeneidad, el tamaño de los granos, la presencia de fisuras, alteraciones, etc. Cabe mencionar que originalmente no se había utilizado la categ oría excelente, pero el transcurso del tiempo hizo necesario diferenciar, dentro del grupo que originalmente se entendía como muy bueno, aquellas de calidad óptima. Es necesario señalar que no se trata de una división en categorías con límites fijos, sino que existe un continuum en la calidad de las rocas para la talla por percusión. A los efectos de controlar el criterio utilizado referido a la calidad de las rocas, trabajamos con muestras volcánicas recuperadas en el área, comparando la determinación de su calidad con su clasificación composicional y su descripción textural. Se llegó a la conclusión de que, para esta muestra, la textura es el factor principal en la determinación de la calidad de la talla, interviniendo como segundo control interdependiente el contenido de los cristales u otras heterogeneidades (Aragón y Franco 1997).

La metodología de registro de fuentes potenciales de aprovisionamiento de recursos líticos utilizada permitió tener una aproximación a la relación entre el tiempo de búsqueda de las materias primas y los resultados obtenidos en distintos 
lugares. Así, es posible saber cuáles son las fuentes de aprovisionamiento que tienen un mayor rendimiento, y cuáles son las que requieren demasiado trabajo para justificar su explotación (ver Torrence 1984). Lo que se mantiene fijo, entonces, es el tiempo de búsqueda. Esto es básico para evaluar costos y beneficios. La metodología empleada permite, entonces, comparar diferentes regiones en términos de la disponibilidad y accesibilidad de su estructura de recursos líticos, y jerarquizarlas de acuerdo con la disponibilidad de determinadas rocas. Sin embargo, esto constituye sólo una aproximación. En los casos en que se observó la existencia de variaciones macroscópicas en la distribución espacial de variedades de un determinado tipo de roca (p.e., la dacita), se seleccionaron muestras para realizar análisis de tierras raras a los efectos de ver si era posible diferenciar entre distintas fuentes de aprovisionamiento secundarias. Realizamos análisis del grupo de elementos correspondientes a las tierras raras (del $\mathrm{La}$ al Lu), utilizando la técnica de activación neutrónica sobre muestras seleccionadas. Tanto la molienda como el análisis por activación neutrónica fueron realizados en Actlabs, Canadá. Para efectuar la comparación entre las muestras se efectuó la normalización de los valores respecto de un condrito estándar (Nakamura 1974), conforme la ecuación: [Muestra]/[Condrito]. Los resultados se graficaron en un diagrama donde los elementos de tierras raras en orden creciente de número atómico se colocan en las abscisas, y la relación de concentración Muestra/condrito se coloca en las ordenadas (Franco y Aragón 2003).

En un trabajo anterior presentamos los resultados obtenidos para el oeste de lago Argentino para las dacitas y calcedonias (Franco y Aragón 2003). En esta oportunidad, ampliaremos la muestra de dacitas y calcedonias naturales, incluyendo ejemplares del este del lago Argentino. Por otra parte, analizaremos artefactos manufacturados sobre dacitas procedentes de distintos sectores del espacio y bloques temporales. Entendemos que estos resultados, integrados a los obtenidos a escala suprarregional para el caso de las obsidianas (Stern y Prieto 1991; Stern et al. 1995a, 1995b; Stern 1999, 2000; Stern y Franco 2000), contribuirán a la discusión referida al rango de acción de las poblaciones humanas en el pasado. Por otra parte, los mismos podrán ser integrados, a largo plazo, con los procedentes de los análisis de isótopos estables sobre restos humanos. La distribución de motivos de pinturas podría, en el futuro, ser otra vía de acceso al problema de la movilidad humana en el extremo sur de Patagonia.

\section{Descripción del área}

El área que nos ocupa se ubica al oeste de la provincia de Santa Cruz (Argentina), entre aproximadamente los $50^{\circ} 10^{\prime}$ y $50^{\circ} 40^{\prime} \mathrm{S}$, y los $73^{\circ} 30^{\prime}$ y $73^{\circ} 30^{\prime}$ y $\operatorname{los} 72^{\circ} \mathrm{W}$ (Figura 1). Abarca el sur del lago Argentino, y está muy próxima a la cordillera de los Andes, que corre de norte a sur al oeste del lago referido, para pasar a tener un recorrido oeste-este al sur del Brazo Sur y de los lagos Roca y Rico, en donde se denomina Sierra Baguales. Por último, vuelve a correr en sentido norte-sur a la altura del río Vizcachas. Las mayores alturas se encuentran al oeste de este espacio, adonde alcanzan los 2400 m.snm. Al este, el área presenta alturas de $200 \mathrm{~m} . \mathrm{snm}$.

Los ríos y arroyos son abundantes en la región. La mayoría desemboca en el sistema lago Argentino-río Santa Cruz. Entre ellos, cabe mencionar el río Centinela, y los arroyos Calafate y Los Perros. Algunos ríos, tales como el Vizcachas, desembocan en el río Coig o Coyle, que desaguan en el Atlántico.

En toda el área existen importantes evidencias de la acción glaciaria, con la presencia de morrenas y bloques erráticos (Feruglio 1944/45; Furque 1973). Se han identificado también cenizas volcánicas, tanto en cotas bajas, en el área del lago Roca como en proximidades del cerro Verlika, en el extremo oriental de Sierra Baguales (Borrero com. pers. y observación personal).

La acción glaciaria influyó en la disponibilidad de materias primas en el área. Las fuentes de aprovisionamiento secundarias son abundantes, mientras que las primarias están localizadas al oeste y sur de este espacio. La bibliografía geológica proporciona un primer punto de partida para aproximarnos a la disponibilidad potencial de las mismas. Por este motivo, comenzaremos con una breve síntesis de la información geológica disponible para toda el área, y expondremos luego los resultados de los muestreos de fuentes potenciales de aprovisionamiento realizados y de los análisis geoquímicos sobre muestras naturales y arqueológicas. 


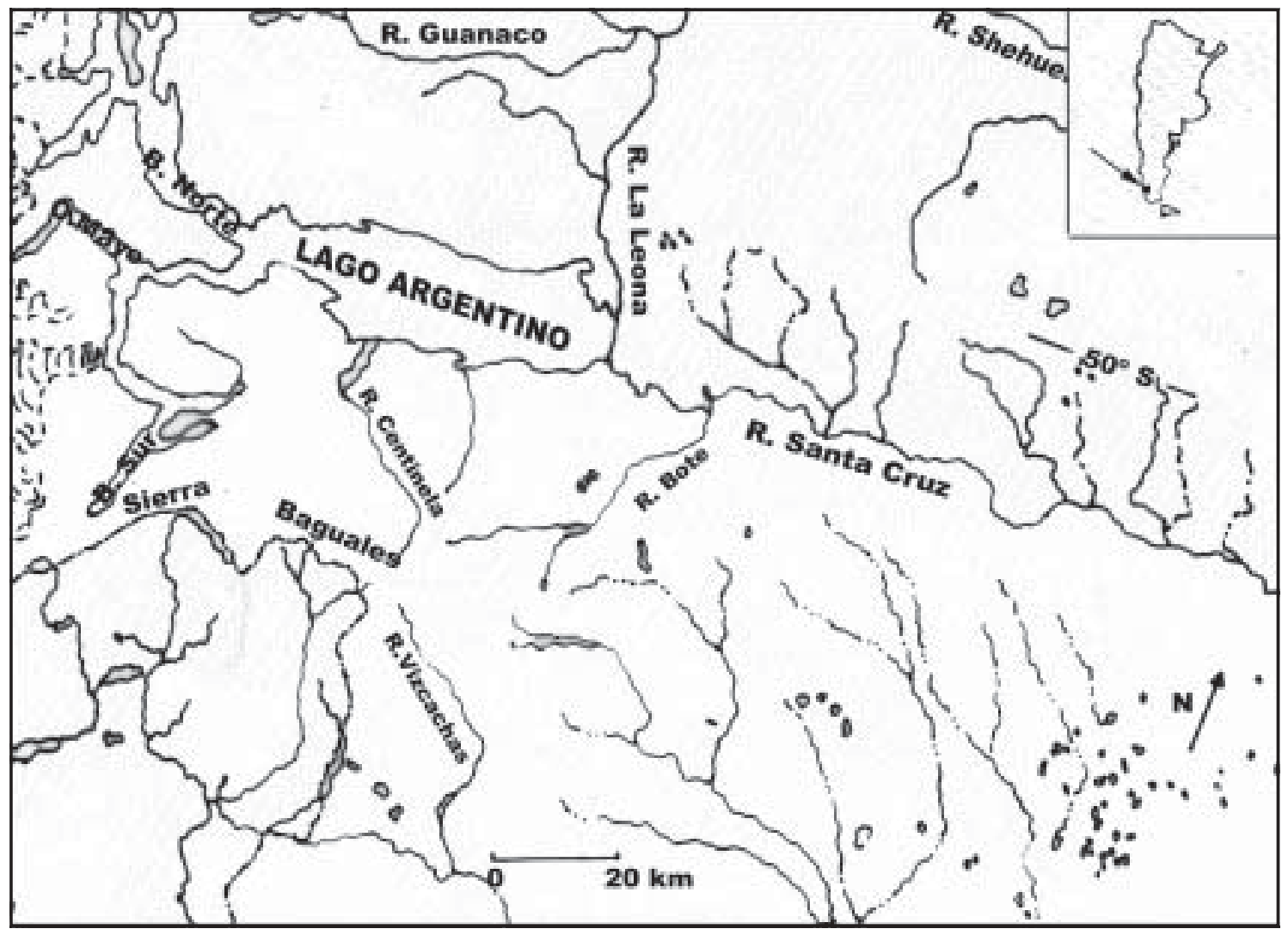

Figura 1. Mapa del sur del lago Argentino, y la ubicación de éste en Argentina.

\section{Antecedentes}

Para sintetizar la información relativa a fuentes primarias potenciales de aprovisionamiento lítico, utilizaremos como guía el trabajo de Nullo (1987 Ms), complementado con información de Feruglio (1944/45), Furque (1973) y Kraemer (1994 Ms).

Las formaciones geológicas que se encuentran en la región tienen cronologías que abarcan desde el Mesozoico (Jurásico) hasta el Holoceno. La bibliografía señala la presencia de fuentes primarias de dacitas, basaltos, ftanitas y también tobas, limolitas y madera silicificada. Las dacitas estarían presentes en el sector occidental de este espacio, formando parte del Complejo El Quemado, que abarca distintas rocas volcánicas (Figura 2). Estas podrían encontrarse también formando parte de los conglomerados de la Formación La Anita. Sin embargo, carecemos de mayor información a este respecto (p.e., referida al tamaño de los nódulos disponibles), motivo por el cual no fueron incluidos en la figura. Cabe señalar que se incluyen dentro de fuentes primarias de aprovisionamiento lítico ya que forman parte de un estrato definido.

Los basaltos se encuentran a lo largo de la Sierra Baguales, continuando con asomos hacia el este en la región de la Meseta de las Vizcachas, El Bote y del Italiano, finalizando al sur en el cerro de la Virgen (Figura 3). Kraemer (1994 Ms) señala que para Muñoz (1980, cit, en Kraemer 1994 Ms) existen, en la región de la Meseta de las Vizcachas, basaltos, rocas piroclásticas y sedimentarias continentales de edad pliocenapleistocena, y basaltos tholeíticos del Pleistoceno Superior. La existencia de dataciones radiométricas sobre roca total por el método K/Ar, permiten diferenciar dos episodios magmáticos diferenciados en el tiempo de diferente dispersión areal (Kraemer 1994 Ms). Furque (1973), por otra parte, realiza sus investigaciones algo más al norte que Nullo. Para este autor, los basaltos corresponden a un solo evento, pudiéndose diferenciar dos épocas de efusiones basálticas: a) las desarrolla- 


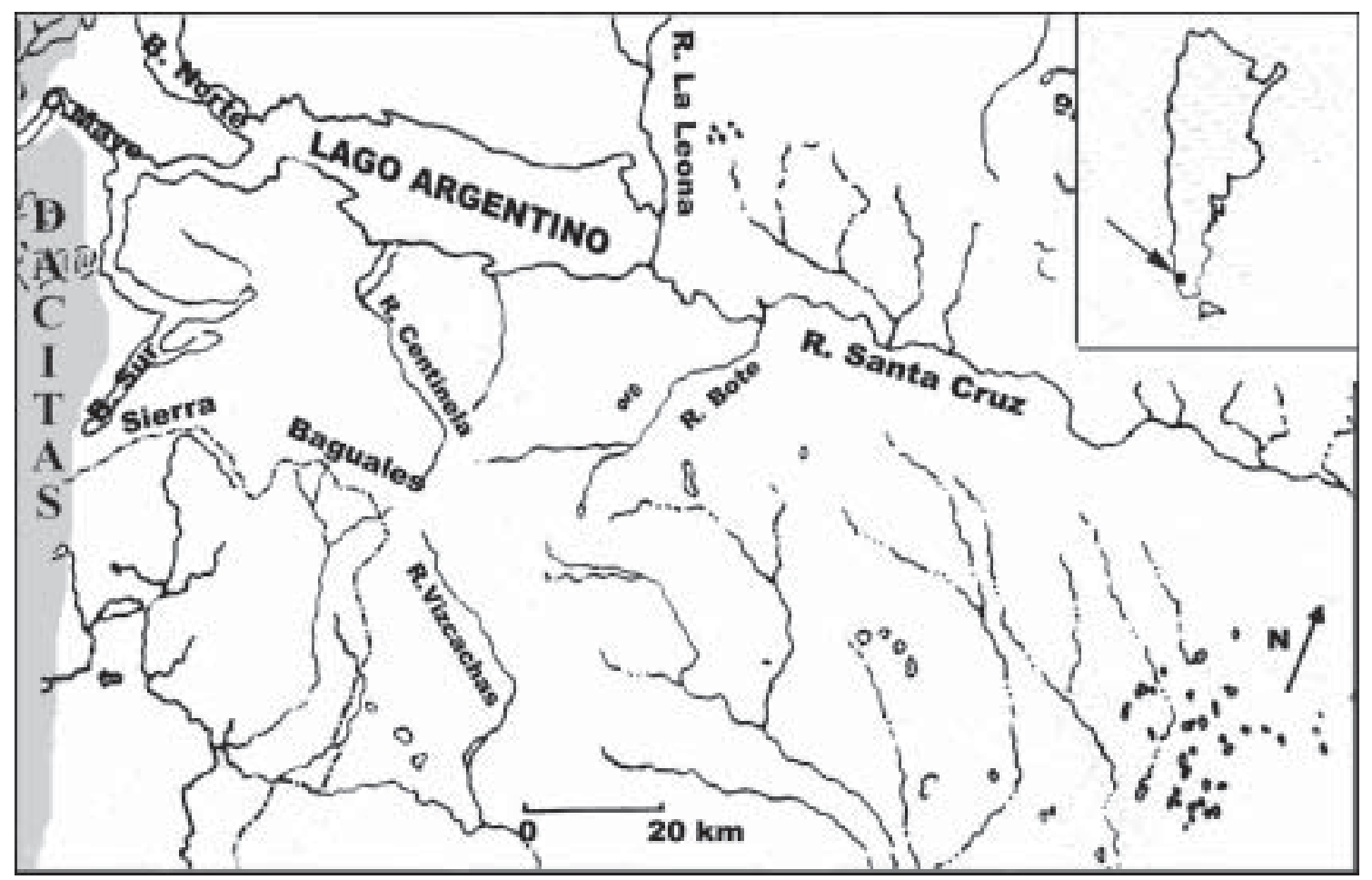

Figura 2. Fuentes primarias potenciales de dacita según la información bibliográfica.

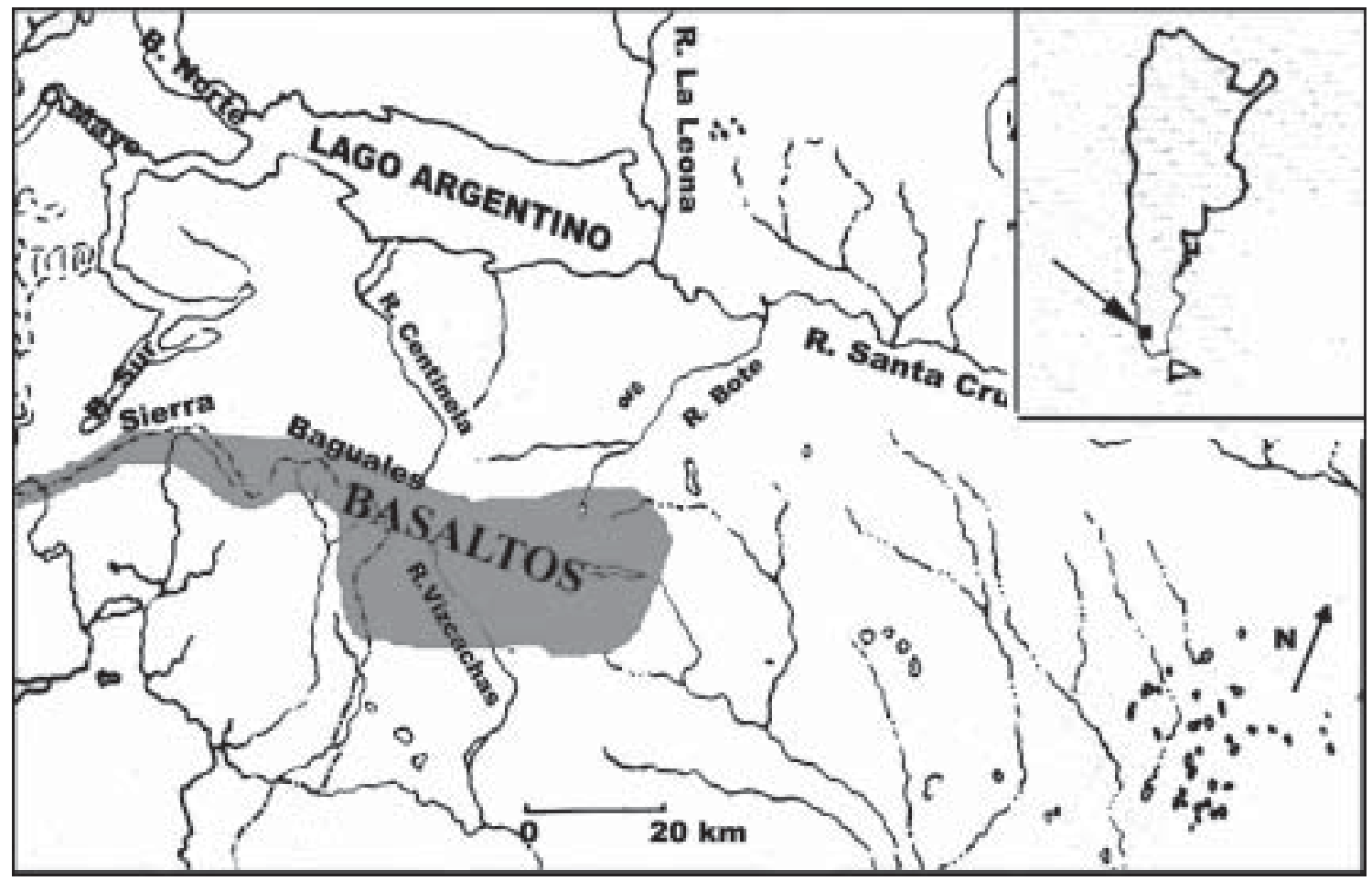

Figura 3. Fuentes primarias potenciales de basalto según la información bibliográfica. 
das en tiempos anteriores a la Formación Santa Cruz y b) las posteriores a esta Formación, probablemente del Pleistoceno Inferior (Furque 1973). La existencia de dos efusiones o episodios magmáticos deja abierta la posibilidad de que dejen marcas geoquímicas distintas que permitan diferenciar las fuentes de aprovisionamiento potenciales de esta materia prima, lo que será explorado en el futuro.

Entre las fuentes primarias, debemos mencionar también que Feruglio (1944/45) señala la presencia de rocas ftaníticas al sur del Brazo Sur, y que Furque (1973) indica la existencia de troncos silicificados en el margen derecho del arroyo $\mathrm{Ca}$ lafate, un poco al norte del puesto de la Estancia 25 de Mayo. Carecemos, sin embargo, de mayores datos en cuanto a su localización.

En el área también son abundantes las fuentes secundarias potenciales de aprovisionamiento lítico. Se trata de depósitos fluviales y glaciares. Furque (1973) considera morrenas internas a los arcos morrénicos poco rebajados por la erosión, que se distribuyen en la región occidental del lago Argentino. Estos constituirían las expresiones del último avance glaciar. Los arcos morrénicos bordean la costa sur del lago Roca y se dirigen hacia el norte, encontrándose en la región entre los cerros Buenos Aires y Frías (Furque 1973). Este autor distingue tres arcos morrénicos terminales, caracterizados por conservar casi intactas sus formas y sin mayor alteración superficial. Poseen grandes bloques erráticos, encontrándose sus principales afloramientos en el borde austral del lago Argentino, entre el cerro Frías y el río Santa Cruz.

En este margen sur del lago Arg entino, entonces, son abundantes los depósitos glaciares. El lago Roca, por ejemplo, se encuentra prácticamente rodeado por los depósitos dejados por el glaciar que ocupaba el valle elaborado entre el Cordón de los Cristales y la península Magallanes (Furque 1973). En la cumbre de este Cordón se encuentran también depósitos glaciares. En cuanto a la costa noreste del Brazo Rico, ha sido rellenada por sedimentos glaciares, lacustres y glacilacustres (Furque 1973). Por otra parte, las investigaciones llevadas a cabo por Feruglio señalan también la presencia de depósitos morrénicos correspondientes a la última glaciación en el valle del río Santa Cruz. Hacia el este, se encontrarían depósitos de drift.
En resumen, la información bibliográfica nos da una primera idea acerca de la disponibilidad de materias primas líticas en la región. En general, existe una alta disponibilidad de las mismas, tratándose frecuentemente de fuentes secundarias. Esto complica la identificación de su procedencia.

Para una primera aproximación a la variabilidad de rocas disponibles decidimos trabajar con una escala espacial amplia. De este modo, la resolución espacial acerca de la procedencia de las materias primas será menor. A continuación presentaremos los resultados exploratorios obtenidos de los muestreos de materias primas.

\section{Resultados de los muestreos de materias primas}

Los resultados obtenidos mostraron la existencia de variabilidad en la disponibilidad de materias primas en el espacio explorado. En general, predomina la dacita, pero existen variaciones en lo referido a las otras materias primas representadas en distintos sectores del espacio (Tabla 1).

Petrográficamente, las dacitas presentan grano muy fino a grueso, encontrándose ejemplares homogéneos y otros que presentan bandas alternantes o sectores esporádicos con diferente tamaño de grano. En algunos casos, presentan abundantes microfenocristales de feldespato y cuarzo de hasta $1 \mathrm{~mm}$. Algunos ejemplares son algo fluidales.

Existen variaciones en el color de las dacitas disponibles en este espacio. Mientras en el oeste del lago Argentino la variedad verde es la más frecuente (Franco 2002; Franco y Aragón 2003), en el este esta variedad es poco abundante. Los análisis muestran, por ejemplo, que al oeste del Brazo Sur dos personas pueden obtener hasta 10 ejemplares de dacita verde en 10 minutos, mientras que al este del Brazo Rico puede adquirir un máximo de seis ejemplares en el mismo tiempo.

\begin{tabular}{|ll|}
\hline Procedencia & Descripción de la roca \\
\hline Río Pelque & Dacita beige \\
Río Pelque & Dacita gris \\
Arroyo los Perros & Calcedonia translúcida \\
Verdadera Argentina & Calcedonia translúcida \\
Verdadera Argentina & Calcedonia translúcida \\
\hline
\end{tabular}

Tabla 1. Procedencia de las muestras naturales de dacita y calcedonia analizadas. 
Por otra parte, en el oeste se encuentran los nódulos de mayores dimensiones (entre 6 y 100 $\mathrm{cm}$, con medias entre 6.83 y $32.75 \mathrm{~cm}$ ) y se han recuperado ejemplares de mejor calidad.

La dacita gris está disponible en todo el espacio explorado, siendo su tamaño y frecuencia menores que los de dacita verde. Para seguir con el ejemplo anterior, en el oeste del Brazo Sur dos personas podrían obtener sólo tres ejemplares de dacita gris (contra los 10 ejemplares ya mencionados de dacita verde). En el oeste de este espacio, esta materia prima se presenta en tamaños entre 11 y $32 \mathrm{~cm}$, estando las medias comprendidas entre 8 y $21.5 \mathrm{~cm}$. Los ejemplares de calidad excelente han sido recuperados al oeste de este espacio, siendo en general su calidad inferior a la recuperada arqueológicamente. Esto podría indicar la existencia de tratamiento térmico, tal como indican los análisis llevados a cabo por Stadler (2002). Hacia el este, sus tamaños y frecuencias disminuyen. La dacita beige, en cambio, es más frecuente al este de este espacio, disminuyendo hacia el oeste.

Para ver si era posible identificar distintas fuentes de aprovisionamiento de dacita, se seleccionaron ejemplares para realizar análisis de tierras raras. Estos incluyeron principalmente muestras de color verde, habiéndose efectuado también sobre ejemplares de color gris y beige. Los análisis indicaron la existencia de tres grupos geoquímicos de dacitas, que poseen una buena correlación espacial. El más occidental procedería probablemente (de acuerdo con su localización geográfica) de la fuente primaria del complejo El Quemado. Carecemos por el momento de datos con respecto a las fuentes primarias de los otros grupos. Los análisis realizados mostraron, por otra parte, que en el caso de esta materia prima, las variaciones en color no pueden ser utilizadas para indicar procedencia (Franco y Aragón 2003).

En esta ocasión, se incluyeron en el análisis dos muestras de dacita (una gris y una beige) procedentes del río Pelque, al este del espacio explorado. En la Figura 4 se observa que la misma se agrupa con las muestras procedentes del río Los Perros, río Bote y río Centinela (sombreadas en gris en la figura). Tiene entonces, una composición semejante a las más orientales hasta ahora analizadas.
Como mencionamos previamente, en el curso del río Centinela las calcedonias translúcidas son frecuentes. Las mismas proceden de rellenos de vesículas volcánicas ubicadas en el curso superior del mismo río. No se han encontrado referencias bibliográficas acerca de estas calcedonias. En el curso inferior, dos personas pueden obtener hasta 12 nódulos de calcedonia en 10 minutos de caminata. Sus tamaños oscilan entre 2 y $7 \mathrm{~cm}$, con una media de $4.7 \mathrm{~cm}$ (Franco 2002). Se ha recuperado también una muestra de calcedonia coloreada. Es necesario señalar que pobladores locales recolectan nódulos de esta materia prima en esta zona, por lo que es probable que los de mayor tamaño en lugares más accesibles hayan desaparecido. Si bien los tamaños de los nódulos son en general pequeños, el hecho de que se trate de materias primas de calidad excelente o muy buena hace que se puedan tallar en mano.

Los análisis de tierras raras efectuados previamente sobre calcedonias permitieron diferenciar variedades procedentes de rellenos de vesículas volcánicas y variedades sedimentarias. Estas últimas eran, en todos los casos, arqueológicas (Franco y Aragón 2003).

En este caso, se agregan al análisis dos muestras de calcedonia procedentes de La Verdadera Argentina, del talud de un afloramiento volcánico, y una muestra de la desembocadura del arroyo Los Perros. En la Figura 5 se grafican los resultados obtenidos en relación con las muestras previamente procesadas. Puede observarse que, si bien se amplía el rango composicional de los ópalos y calcedonias sedimentarias, se mantiene la distribución de la curva, no siendo posible por el momento distinguir dentro de estas muestras otros subgrupos que tengan significación de fuentes. La Figura 6 indica la procedencia de estas calcedonias y de las procedentes de rellenos de vesículas volcánicas.

\section{Resultados de los análisis geoquímicos de las muestras arqueológicas}

Sobre la base de los resultados obtenidos con muestras naturales de dacita y calcedonia, se realizaron análisis de artefactos arqueológicos datados entre $c a .9700$ y 1000 años AP, y localizados tanto en los sectores occidentales como orientales de este espacio. 


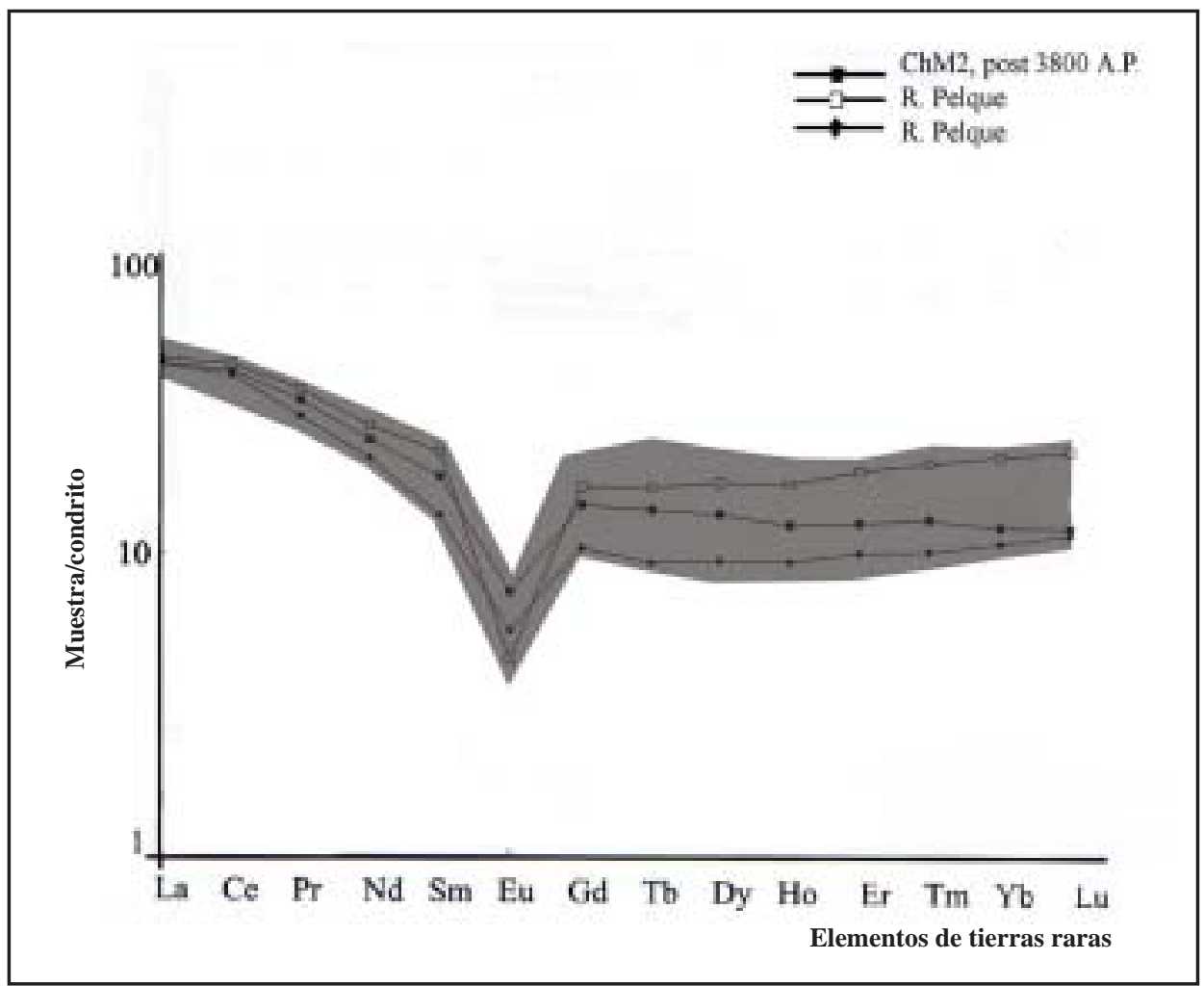

Figura 4. Diagrama de tierras raras correspondientes a muestras de dacita naturales procedentes del río Pelque y a una muestra arqueológica correspondiente a los depósitos superiores de Chorrillo Malo-2. El sombreado del grupo corresponde a la Figura 2 de Franco y Aragón (2003).

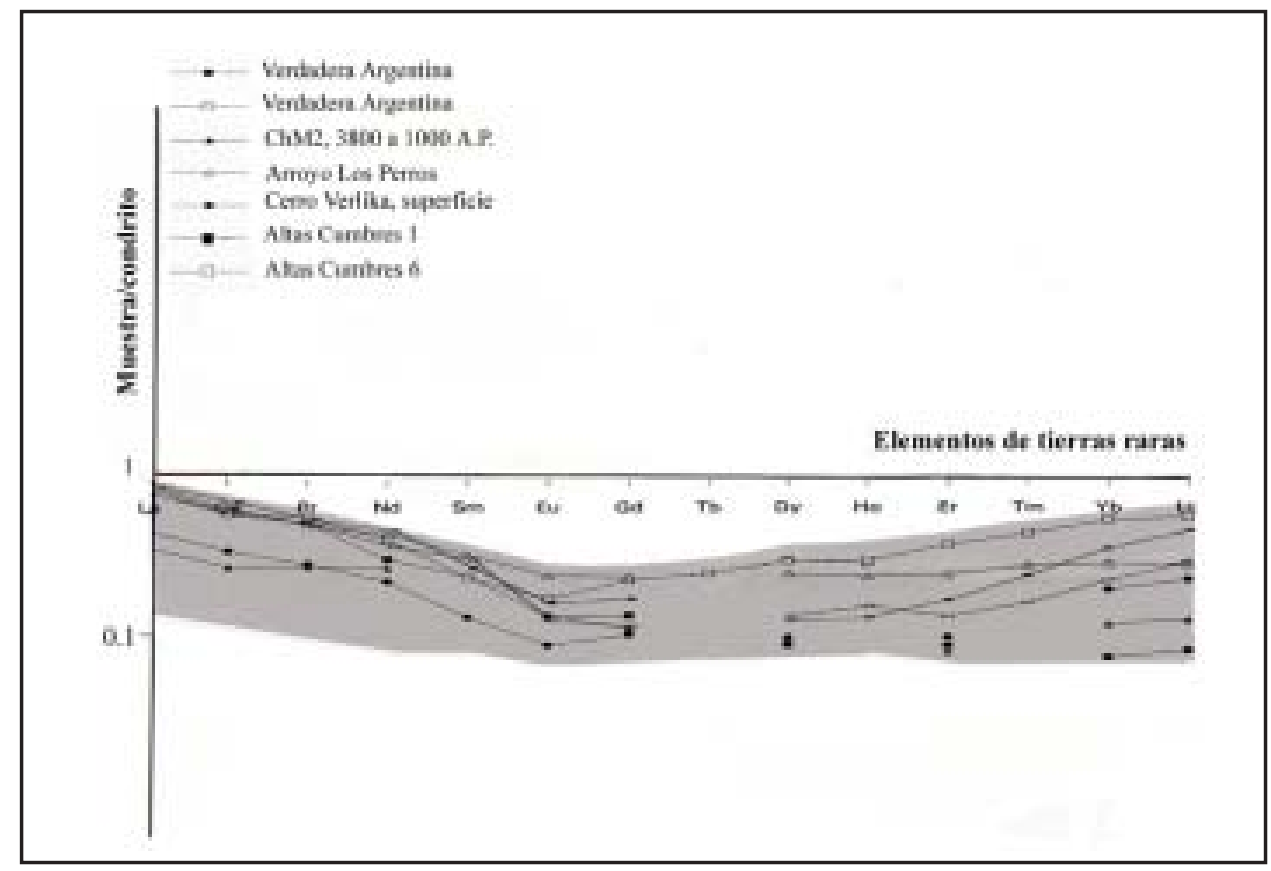

Figura 5. Diagrama de tierras raras correspondientes a muestras de calcedonia naturales sedimentarias. El sombreado fue modificado de la Figura 3 de Franco y Aragón (2003). 


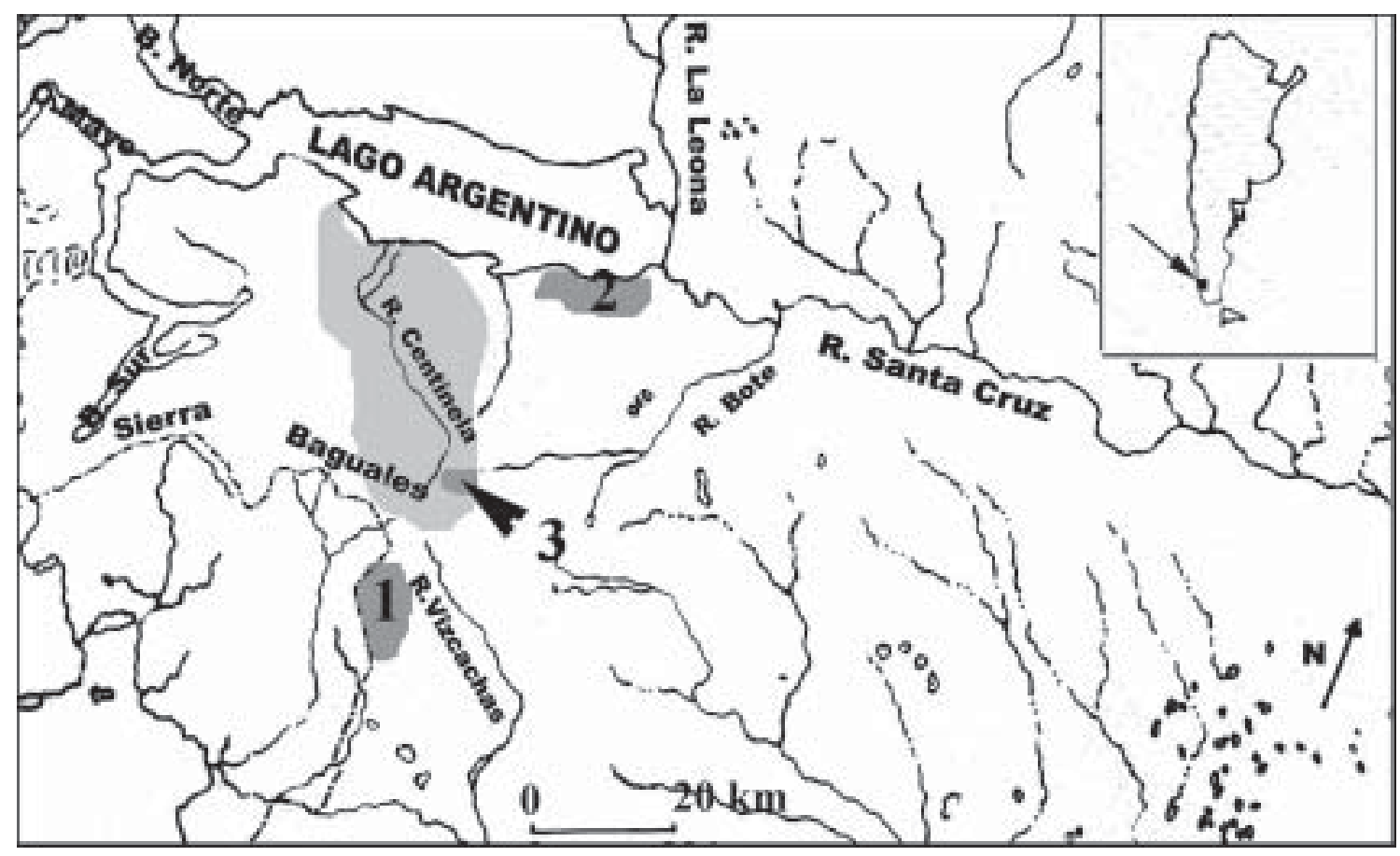

Figura 6. Distintas variedades de calcedonia identificadas. En gris claro se indican las procedentes de rellenos de vesículas volcánicas. En gris oscuro, se indica la procedencia de las variedades sedimentarias: el número 1 indica el área de Verdadera Argentina, el 2 la desembocadura del arroyo Los Perros, y el 3 la cuenca superior del río Centinela.

Se analizaron muestras de dacita verde de artefactos recuperados en estratigrafía en los sitios Chorrillo Malo-2, Punta Bonita-2, Charles Fuhr2, y muestras de superficie procedentes de Rincón del Chingolo y de proximidades de La Esperanza (Carballo Marina et al. 1999; Franco y Borrero 2003; Borrero et al. 2004 Ms) (Tabla 2 y Figura 7).

En las figuras 4, 8 y 9 se grafican los resultados obtenidos en relación con las muestras previamente procesadas, que se sombrean. En este caso, decidimos plotear los grupos composicionales de manera independiente a los efectos de evitar superposiciones.

La mayoría de las muestras procedentes de Chorrillo Malo-2, al igual que las de Punta Bonita-2 y Charles Fuhr-2 se corresponden con las muestras naturales recuperadas en los depósitos de Brazo Sur, laguna 3 de Abril, lago Roca, cerro Verlika y parte de las muestras del río Rico. Se trata entonces, de muestras muy próximas al lugar en el que está localizado Chorrillo Malo-2. Constituye por lo tanto, en este caso, una materia prima inmediatamente disponible (sensu Meltzer
1989). Los resultados obtenidos son consistentes con los procedentes de los análisis artefactuales, que sugieren la realización de actividades iniciales de talla en esta materia prima (Franco 2002). En el caso de este sitio, las muestras proceden de distintos bloques temporales, datados entre $c a$. 9700 y 1000 años AP.

Esta materia prima se encuentra a mayor distancia de los sitios recuperados en Punta Bonita-2 y Charles Fuhr-2, lo que indicaría que se transporta hacia espacios más orientales. Se necesitan, sin embargo, mayor cantidad de análisis geoquímicos en muestras naturales de este sector para evaluar si la misma no está disponible más hacia el oriente.

Una lasca secundaria entera de dacita verde correspondiente a los depósitos superiores del sitio Chorrillo Malo-2 tiene una composición similar a muestras naturales recuperadas desde el río Centinela hacia el este (Figura 4). Se trata, por lo tanto, de una muestra que podría provenir de sectores algo más alejados del sitio.

Las muestras arqueológicas procedentes del sector más oriental de este espacio (Rincón del 


\begin{tabular}{|c|c|c|c|}
\hline Procedencia & Datación & $\begin{array}{l}\text { Clasificación de la muestra } \\
\text { (sensu Aschero } 1983 \text { Ms) }\end{array}$ & $\begin{array}{c}\text { Descripción } \\
\text { de la roca }\end{array}$ \\
\hline Chorrillo Malo-2 & Entre $c a .9700$ y 6100 años AP & Lasca angular & Dacita verde \\
\hline Chorrillo Malo-2 & Entre $c a .6100$ y 3800 años AP & Lasca angular & Dacita verde \\
\hline Chorrillo Malo-2 & Entre $c a .3800$ años y 3100 años AP & Lasca angular & Dacita verde \\
\hline Chorrillo Malo-2 & Entre $c a .3100$ años y 1000 años AP & Lasca con dorso & Dacita verde \\
\hline Chorrillo Malo-2 & Entre $c a .3100$ años y 1000 años AP & Lasca angular & Dacita verde \\
\hline Chorrillo Malo-2 & Entre $c a .3100$ años y 1000 años AP & Lasca secundaria & Dacita verde \\
\hline Punta Bonita-2 & ca. 2500 años AP & Lasca angular & Dacita verde \\
\hline Punta Bonita-2 & ca. 2500 años AP & Lasca angular & Dacita verde \\
\hline Charles Fuhr-2 & ca. 1100 años AP & Lasca angular & $\begin{array}{l}\text { Dacita verde con } \\
\text { impurezas negras }\end{array}$ \\
\hline Rincón del Chingolo & Sin datos (sup.) & Lasca angular & Dacita verde \\
\hline $\begin{array}{l}\text { Proximidades de } \\
\text { La Esperanza }\end{array}$ & Sin datos (sup.) & Lasca secundaria & Dacita verde \\
\hline
\end{tabular}

Tabla 2. Procedencia y características de las muestras arqueológicas de dacita analizadas.

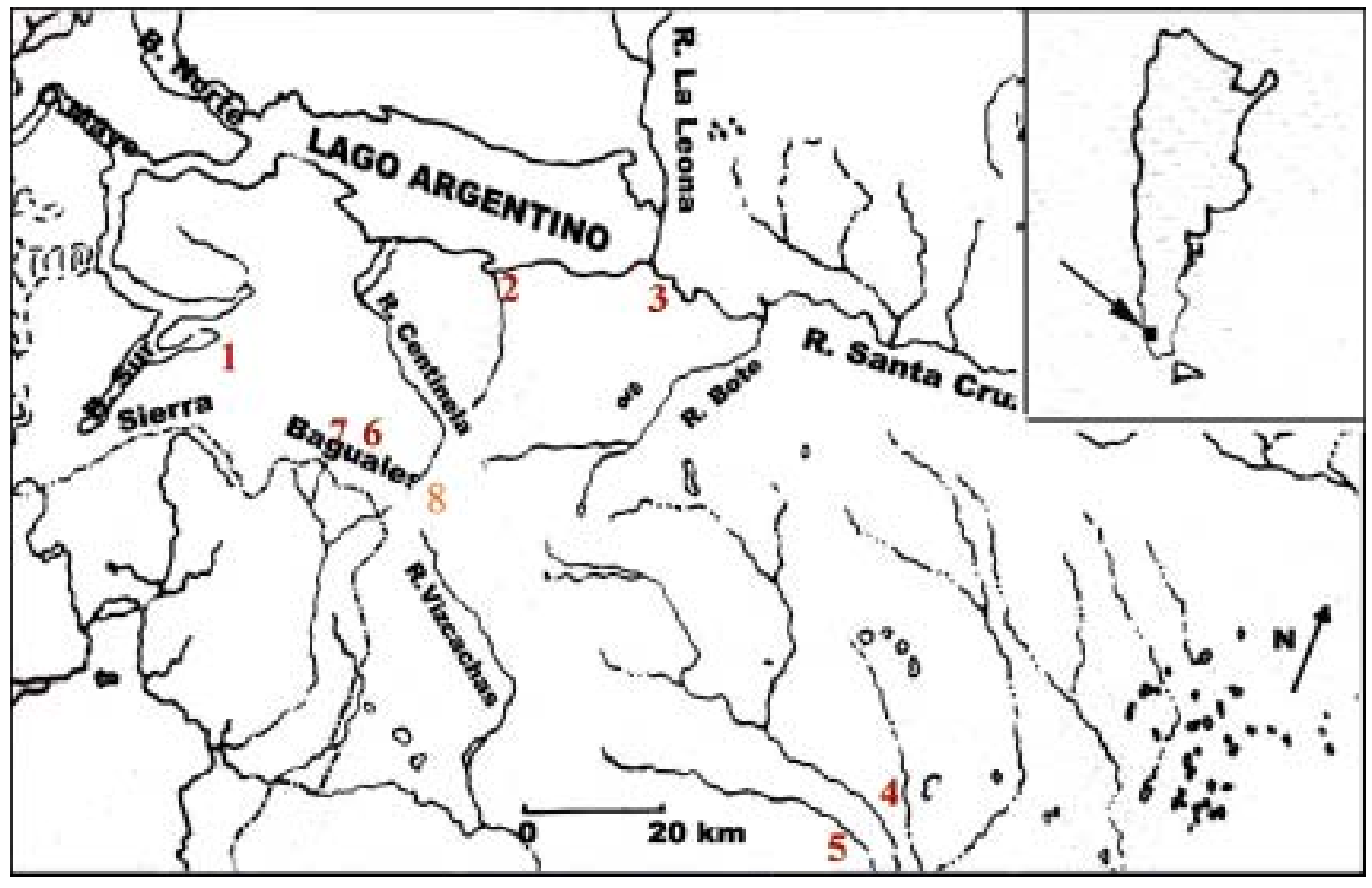

Figura 7. Procedencia de las muestras arqueológicas analizadas mediante tierras raras. 1) Chorrillo Malo-2; 2) Punta Bonita-2; 3) Charles Fuhr-2; 4) Rincón del Chingolo; 5) proximidades Esperanza; 6) Altas Cumbres-1; 7) Altas Cumbres-6; 8) curso superior del río Centinela, superficie. 


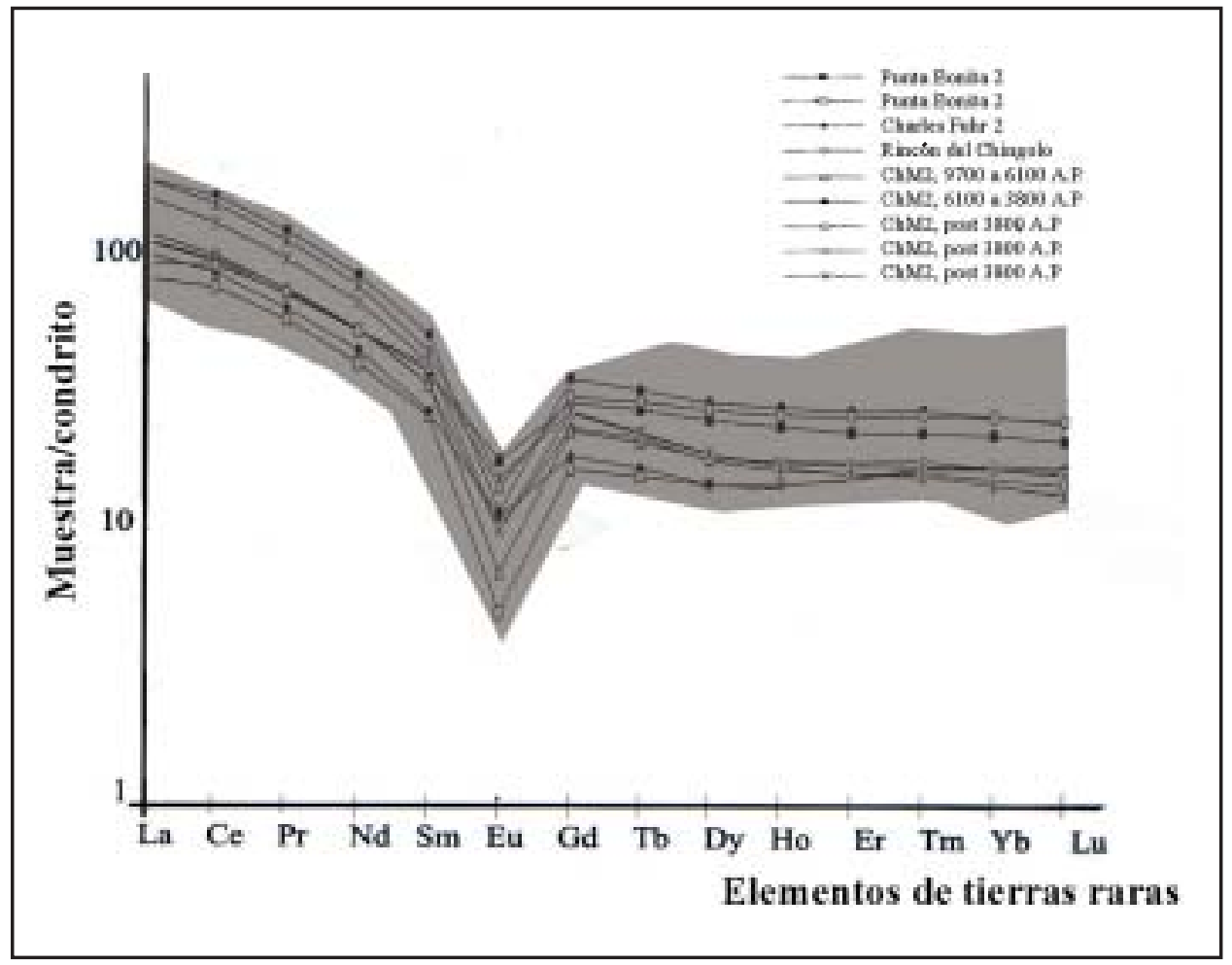

Figura 8. Diagrama de tierras raras correspondiente a muestras de dacitas arqueológicas de los sitios Chorrillo Malo-2, Punta Bonita-2 y Charles Fuhr-2, y a la muestra de superficie de Rincón del Chingolo. El sombreado del grupo corresponde a la Figura 2 de Franco y Aragón (2003).

Chingolo y proximidades de Esperanza) presentan en el primer caso semejanzas con las muestras más occidentales, recuperadas en el Brazo Sur, laguna 3 de Abril, lago Roca, cerro Verlika y parte de las muestras del lago Rico (Figura 8), y en el segundo, semejanzas con las muestras composicionales recuperadas en el arroyo Calafate y en el río Rico (Figura 9).

Los resultados indican por un lado, que la totalidad de la variabilidad geoquímica de las muestras de dacita verde ha sido muestreado. Por otro lado, como ya lo hemos mencionado, plantean la necesidad de efectuar mayor cantidad de análisis en muestras naturales de dacita verde disponibles en los sectores orientales de este espacio (desde el arroyo Calafate hacia el este), para evaluar si están disponibles de manera natural o si son transportadas por las poblaciones humanas.

En el caso de las calcedonias, se realizaron análisis de artefactos confeccionados sobre calcedonia y ópalo recuperados en superficie en cotas altas, en los sitios Altas Cumbres-1 y 6, y en un sitio al aire libre próximo al curso superior del río Centinela (Figura 7). Los análisis mostraron que en todos los casos se trata de calcedonias de origen sedimentario. Las evidencias geológicas apuntarían a que las mismas proceden del área cercana a Sierra Baguales (Tabla 3). En este sentido, cabe señalar que en el caso de la calcedonia con impurezas de óxidos no determinados, los análisis artefactuales indican un decrecimiento en la frecuencia y tamaño de los mismos en relación con el aumento de la distancia a esta área, sugiriendo el aprovisionamiento directo de las mismas (Franco 2004 Ms). El patrón es menos claro en el caso del ópalo con impurezas.

Cabe señalar que un problema importante para el análisis de calcedonias y ópalos lo constituye el hecho de que estas materias primas son altamente economizadas, recuperándose en general únicamente lascas o fragmentos de lascas muy pequeños, que no alcanzan el límite requerido para los análisis de tierras raras (más de 3 gr). 


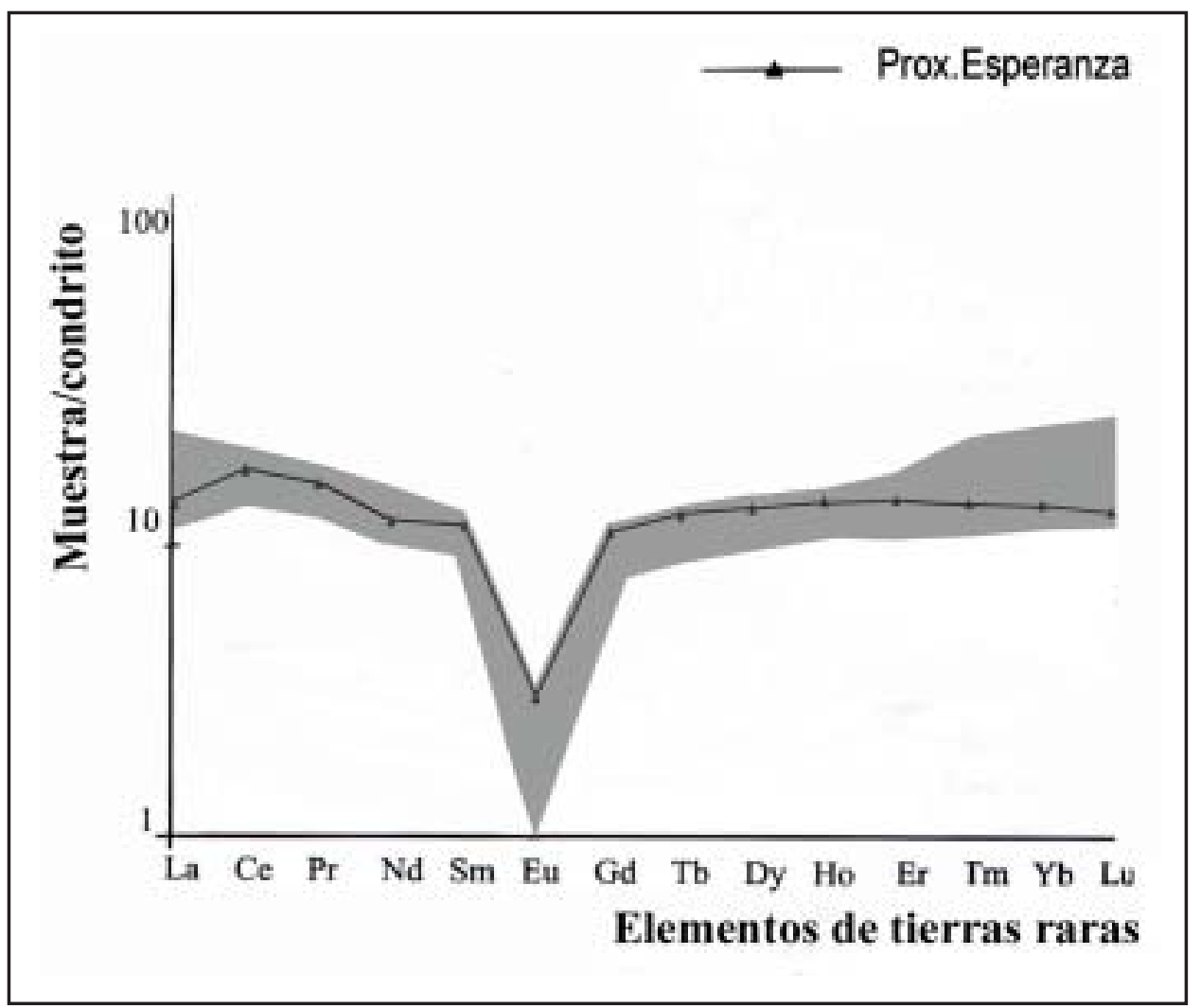

Figura 9. Diagrama de tierras raras correspondiente a la muestra arqueológica de superficie de proximidades de Esperanza. El sombreado del grupo corresponde a la Figura 2 de Franco y Aragón (2003) modificado.

\begin{tabular}{|llll|}
\hline Procedencia & Datación & \multicolumn{1}{c|}{$\begin{array}{c}\text { Clasificación de la muestra } \\
\text { (sensu Aschero 1983 Ms) }\end{array}$} & Descripción de la roca \\
\hline Altas Cumbres-1 & Sin datos (sup.) & $\begin{array}{l}\text { Fragmento no diferenciado de artefacto } \\
\text { formatizado }\end{array}$ & Calcedonia translúcida y ópalo \\
Altas Cumbres-6 & Sin datos (sup.) & Lasca de arista & Calcedonia con impurezas \\
Cerro Verlika & Sin datos (sup.) & Lasca de arista & Opalo con impurezas \\
\hline
\end{tabular}

Tabla 3. Procedencia de las muestras arqueológ icas de calcedonia y ópalo analizadas.

\section{Consideraciones generales}

Los resultados obtenidos de los análisis de tierras raras apuntan hacia la utilización de dacita verde inmediatamente disponible en los sectores más occidentales de este espacio. Estos resultados son consistentes con aquellos procedentes de los análisis de las características de los artefactos, que sugieren la existencia de actividades iniciales de talla de esta materia prima. Sin embarg o, algunos de estos artefactos podrían haber sido transportados mayores distancias. Sería el caso, por ejem- plo, de los cuchillos y raederas confeccionados sobre núcleos preparados (sensu Nami 1992b, 1997). Los núcleos han sido recuperados en estos sectores más occidentales, en lugares con abundante dacita verde, lo que es consistente con estrategias de economía de materia prima (Franco 2002, 2004). Por otra parte, vale la pena señalar que los análisis geoquímicos realizados sobre artefactos de dacita verde recuperados en el sector más oriental indican que los mismos poseen características semejantes a las materias primas recuperadas al oeste de este espacio, dejando abier- 
ta la posibilidad para el traslado de estas materias primas hacia el este. Sin embargo, es necesario realizar mayor cantidad de análisis sobre muestras naturales de dacita verde de los sectores más orientales para evaluar si es posible que las mismas estén también disponibles en esta área.

Los análisis efectuados sobre calcedonias y ópalos apuntan a la posibilidad de diferenciar macroscópicamente algunas variedades sedimentarias. Por otra parte, indican que las mismas se conservarían y trasladarían a mayores distancias que la variedad verde de dacita. Cabe señalar que la mayoría de las muestras arqueológicas analizadas, tanto en este trabajo como en otro anterior (Franco y Aragón 2003), corresponden a variedades sedimentarias. Algunas de estas materias primas, como la calcedonia con impurezas, están presentes desde los momentos más tempranos de ocupación del área, lo que indica que las poblaciones conocían las fuentes de aprovisionamiento, probablemente ubicadas en proximidades de Sierra Baguales, desde momentos anteriores. Otras materias primas, como el ópalo con impurezas, se hace presente en el registro arqueológico del área recién con posterioridad al 3800 AP, momento en que este espacio está siendo ocupado de manera efectiva (Franco 2002), e indicando probablemente un mejor conocimiento del área.

Los análisis de tierras raras han mostrado que no puede distinguirse de manera macroscópica las variedades translúcidas de calcedonia. Estos aná- lisis sólo permiten separar entre las variedades procedentes de rellenos de vesículas volcánicas de las sedimentarias.

Finalmente, consideramos los resultados obtenidos hasta el momento como exploratorios y entendemos que será necesario ampliar el número de muestras analizadas, tanto en lo que respecta a muestras naturales como arqueológicas. Creemos que los mismos serán muy importantes para evaluar rangos de acción y movimiento de las poblaciones humanas, y deberán ser complementados con otras líneas de evidencias, como por ejemplo, análisis de isótopos estables sobre huesos humanos.

Agradecimientos A Luis A. Borrero, quien impulsó los análisis de distribución de materias primas en el área del lago Argentino. A un revisor anónimo. A todos los miembros del equipo que participaron en los trabajos de muestreos de materias primas y en la recuperación de los artefactos arqueológicos. Estos trabajos fueron realizados en el marco de los proyectos PIP 4954 "Magallania II" (CONICET), proyectos PICT 040807 "Distribuciones arqueológicas en escala suprarregional" y 04-9498 "Modos de interacción de las poblaciones humanas de la Patagonia meridional" (Agencia Nacional de Promoción Científica y Técnica), F 133 "Circulación humana en el extremo sur de Patagonia" y F 140 ("Variaciones regionales y diseños artefactuales compartidos en el extremo sur de Patagonia y norte de Tierra del Fuego (Universidad de Buenos Aires).

\section{REFERENCIAS CITADAS}

AMICK, D. S., 1994. Technological organization and the structure of inference in lithic analysis: An examination of Folsom hunting behavior in the American Southwest. En The organization of North American prehistoric chipped stone tool technologies, P. J. Carr (Ed.), pp. 9-34. International Monographs in Prehistory. Archaeological Series 7. Ann Arbor, Michigan.

ARAGON, E. y N. V. FRANCO, 1997. Características de rocas para la talla por percusión y propiedades petrográficas. Anales del Instituto de la Patagonia (Serie Ciencias Humanas) 25: 87-199.

ASCHERO, C. A., 1983 Ms. Ensay o para una clasificación morfológica de artefactos líticos aplicada a estudios tipológicos comparativos. Informe al CONICET. Revisión 1983.
BAMFORTH, D. B., 1986. Technological efficiency and tool curation. American Antiquity 51 (1): 38-50.

BECK, C. y G. T. JONES, 1990. Toolstone selection and lithic technology in early Great Basin prehistory. Journal of Field Archaeology 17: 283-299.

BORRERO, L. y F. CARBALLO MARINA, 1998. Proyecto Magallania: La cuenca superior del río Santa Cruz. En Arqueología de la Patagonia Meridional (Proyecto Magallania), L. Borrero (Comp.), pp. 11-27. Editorial Búsqueda de Ayllu, Concepción del Uruguay.

BORRERO, L., N. V. FRANCO, F. M. MARTIN, R. BARBERENA, R. GUICHON, J. B. BELARDI y C. FAVIER DUBOIS, 2004 Ms. Arqueología del este de Baguales. Enviado a Actas del XIV Congreso Nacional de Arqueología Argentina. Rosario. 
CARBALLO MARINA, F. M., L. BORRERO, N. V. FRANCO, J. B. BELARDI, V. D. HORWITZ, A. S. MUÑOZ, P. CAMPAN, F. M. MARTIN, F. BORELLA, M. F. GARCIA, F. MUÑOZ, F. SAVANTI y J. L. LANATA, 1999. Arquelogía de la costa de lago Argentino, río La Leona y pampas altas intermedias. Prehistoria 3: 13-33.

DUNBAR, J., 1991. Resource orientation of Clovis and Suw annee Age paleoindian sites in Florida: En Clovis: Origins and adaptation, R. Bonnichsen y K. Turmire (Ed), pp. 175-184. Center for the Study of the First Americans. Oregon State University. Corvallis, Oregon.

FERUGLIO, E., 1944-45. Estudios geológicos y glaciológicos en la región del Lag o Argentino (Patag onia). Boletín de la Academia Nacional de Ciencias de Córdoba 37 (1): 3-255. Córdoba.

FRANCO, N. V., 1991. El aprovisionamiento de los recursos líticos en el Area Interserrana Bonaerense. Shincal 3 (2):39-51.

FRANCO, N. V., 1994. Maximización en el aprovechamiento de los recursos líticos. Un caso analizado en el Area Interserrana Bonaerense. En Arqueología de cazadores recolectores. Límites, casos y aperturas, J. L. Lanata y L. Borrero (Comps.), pp. 75-88. Arqueología Contemporánea 5. Edición especial. Buenos Aires.

-2002. Estrategias de utilización de recursos líticos en la cuenca superior del río Santa Cruz. Tesis doctoral. Facultad de Filosofía y Letras, Universidad de Buenos Aires, Buenos Aires.

_2004. Rangos de acción, materias primas y núcleos preparados al sur y oeste de lago Argentino. Actas de las $V$ Jornadas de Arqueología de la Patagonia. Buenos Aires. En prensa.

-2004 Ms. Los artefactos líticos y la información sobre el comportamiento humano en grandes espacios. Trabajo presentado al Simposio "Artefactos, movilidad y funcionalidad de sitios: Problemas y perspectivas", XV Congreso Nacional de Arqueología Argentina. Río Cuarto, Córdoba.

FRANCO, N. V. y E. ARAGON, 2003. Muestreo de fuentes potenciales de aprovisionamiento lítico: Un caso de estudio. En Del mar a los salitrales. Diez mil años de historia pampeana en el umbral del tercer milenio, D. Mazzanti, M. Berón y F. Oliva (Eds.), pp. 243-250. Universidad Nacional de Mar del Plata y Sociedad Argentina de Antropología, Mar del Plata.

FRANCO, N. V. y L. BORRERO, 1999. Metodología de análisis de la estructura regional de recursos líticos. En En los tres reinos: Prácticas de recolección en el Cono Sur de América, C. Aschero, A. Korstanje y P. M. Vuoto (Eds.), pp. 27-37. Ediciones Magna Publicaciones, San Miguel de Tucumán.

2003. Chorrillo Malo-2: Initial peopling of the Upper Santa Cruz Basin. En Where the south winds blow. Ancient evidences of Paleo South Americans, L. Miotti, M. Salemme y N. Flegenheimer (Eds.), pp. 149-152. Center for the Studies of the First Americans (CSFA) y Texas A\&M University Press, Texas.

FRANCO, N. V. y M. F. GARCIA, 1994 Ms. Análisis de núcleos procedentes de la costa de Tierra del Fuego y de la cuenca superior del río Santa Cruz (Rep. Argentina). Ponencia presentada en el XI Congreso Nacional de Arqueología Argentina, San Rafael.

FURQUE, G., 1973. Descripción geológica de la hoja 58b, Lago Argentino. Provincia de Santa Cruz. Carta Geológica de la hoja 58 b, lago Argentino. Boletín Servicio Nacional Minero Geológico 140.

GENESTE, J. M., 1988. Les industries de la Grotte Vaufrey: Technologie du débitage, économie et circulation de la matiere premiere lithique. En La Grotte Vaufrey a Cenac et Saint-Julien (Dordogne), paléoenvironments, chronologie et activités humaines, J. P. Rigaud (Ed.), pp. 441-518. Mémoires de la Société Préhistorique Francaise 19, París.

KRAEMER, P. E., 1994 Ms. Tectónica de placas y los grandes corrimientos geológicos tangenciales en la parte austral de Sudamérica. Cátedra de Geología Regional Argentina. Facultad de Ciencias Exactas Físicas y Naturales, Universidad Nacional de Córdoba, Córdoba.

LEPPER, B. T. y D. MELTZER, 1991. Late Pleistocene human occupation of the Eastern United States. En Clovis: Origins and adaptation, R. Bonnichsen y K. Turmire (Eds.), pp. 175-184. Center for the Study of the First Americans. Oregon State Universiy, Corvallis.

LUEDTKE, B. E., 1979. The identification of sources of chert artifacts. American Antiquity 44 (4): 744-756.

LURIE, R., 1989. Lithic technology and mobility strategies: The Koster site Middle Archaic. En Time, energy and stone tools, R. Torrence (Ed.), pp. 46/56. Cambridge University Press. Cambridge.

MELTZER, D., 1989. Was stone exchanged among Eastern North American paleoindians? En Eastern paleoindian lithic resource use, C. J. Ellis y J. Lothrop (Eds.), pp. 11-39. Westview Press, Boulder.

NAKAMURA, N., 1974. Determination of Ree, Ba, Fe, Mg, $\mathrm{Na}$, and $\mathrm{K}$ in carbonaceos and ordinary chondrites. Geochimica et Cosmochimica Acta 38: 757-775.

NAMI, H., 1992 a. El subsistema tecnológico de la confección de instrumentos líticos y la explotación de los recursos del ambiente: Una nueva vía de aproximación. Shincal 2: 33-53.

_ 1992 b. Noticia sobre la existencia de técnica "levallois" en península Mitre, extremo sudoriental de Tierra del Fuego. Anales del Instituto de la Patagonia 21: 73-80.

-1997. Más datos sobre la existencia de núcleos preparados y lascas predeterminadas en la Patagonia Austral. Anales del Instituto de la Patagonia 25: 223-227.

NELSON, M. C., 1987. Site content and structure: Metate quarries and workshops in the Maya Highlands. En Lithic 
studies among the contemporary Highland Maya, B. Hayden (Ed.), pp. 120-159. The University of Arizona Press, Tucson.

NULLO, 1987 Ms. Descripción geológica de la hoja 59 ab, Cordón de los Cristales, provincia de Santa Cruz.

STADLER, N. 2002. El uso del tratamiento térmico sobre las materias primas líticas en el área de lag o Argentino. Tesis de licenciatura. Universidad de Buenos Aires.

STERN, C., 1999. Black obsidian from Central-South Patagonia: Chemical characteristics, sources and regional distribution of artifacts. En Soplando en el viento... Actas de las III Jornadas de Arqueología de Patagonia, pp. 221-234. Neuquén, Buenos Aires.

2000. Sources of obsidian artifacts from the Pali Aike, Fell's Cave and Cañadón La Leona archaeological sites in southernmost Patagonia. En Desde el país de los gigantes. Perspectivas arqueológicas en Patagonia, J. B. Belardi, F. Carballo Marina y S. Espinosa (Eds.), pp. 4355. Editorial Universidad Nacional de la Patagonia Austral, Río Gallegos.
STERN, C. y N. V. FRANCO, 2000. Obsidiana gris verdosa veteada de la cuenca superior del río Santa Cruz, extremo sur de Patagonia. Anales del Instituto de la Patagonia 28: $265-273$.

STERN, C. y A. PRIETO, 1991. Obsidiana verde de los sitios arqueológicos en los alrededores del mar de Otway, Magallanes, Chile. Anales del Instituto de la Patagonia 20: 139-144.

STERN, C., F. MENA, C. ASCHERO y R. GOÑI, 1995 a. Obsidiana negra de los sitios arqueológicos en la precordillera de Patagonia central. Anales del Instituto de la Patagonia 23: 111-118.

STERN, C., A. PRIETO y N. V. FRANCO, 1995 b. Obsidiana negra en sitios arqueológicos de cazadores recolectoes terrestres en Patag onia austral. Anales del Instituto de la Patagonia 23: 105-109.

TORRENCE, R., 1984. Monopoly or direct access? Industrial organization at the Melos obsidian quarries. En Prehistoric quarries and lithic production, J. E. Ericson y B. A. Purdy (Ed.), pp. 49-64. Cambridge University Press. Cambridge. 